\title{
Ultrasound follow up: Is an undetected spontaneous expulsion of stone fragments a sign of extracorporeal shock wave treatment failure in kidney stones?
}

\author{
Grazia Bianchi, Diego Marega, Roberto Knez, Stefano Bucci, Carlo Trombetta \\ Department of Urology, University of Trieste, Cattinara Hospital, Trieste, Italy.
}

\begin{abstract}
Summary Introduction. After extracorporeal lithotripsy (SWL), a spontaneous expulsion of fragments is often reported. The aim of this study is to demonstrate the presence of a stone free status or the presence of clinically insignificant residual fragments (CIRFs, defined as "asymptomatic, noninfectious, $\leq 3 \mathrm{~mm}$ fragments") in people with undetected spontaneous expulsion.

Materials and methods. Between May and September 2017, we performed a total of 87 treatments. The device used was a Storz Medical Modulith ${ }^{\circledR}$ SLK. All the patients were treated in prone position to reduce respiratory movements and underwent sonography before and four to eight weeks after the treatment. An in line ultrasound targeting was possible with all the stones. People lost to follow up or with ureteral stones were excluded. Patients were divided in groups according to gender, previous treatments, stone diameter and position.

Results. We enrolled 73 patients. 57 patients had a single stone and 16 multiple stones. A mean number of 3044 shock waves was administered with a maximum average energy of $0.68 \mathrm{mj} / \mathrm{mmq}$. At follow up, 41 patients (56.2\%) were found stone free or with CIRFs. The association between undetected expulsion and the presence of CIRFs is considered to be not statistically significant $(p=0.89)$. Among patients with CIRFs, $25 / 41$ didn't report expulsion. Taking in account the groups our population was divided in, according to gender $(p=0.36)$, previous treatments $(p=0.44)$, stone diameter $(p=0.28)$ and stone position $(p=0.35)$, the association between undetected spontaneous expulsion and presence of CIRFs was never statistically significant.

Conclusions. An undetected spontaneous expulsion of stone fragments could not be considered a sign of SWL treatment failure. The association between undetected expulsion and presence of CIRFs is never statistically significant if gender of the patients, previous treatments, stone diameter and stone position are considered.
\end{abstract}

KEY WORDS: Lithotripsy; Fragment expulsion; Clinically insignificant fragments; SWL.

Submitted 6 June 2018; Accepted 19 August 2018

\section{INTRODUCTION}

After extracorporeal shock waves lithotripsy (SWL), a spontaneous expulsion of fragments is often reported. During the first medical examination after the treatment, the patient is always asked if he had a renal colic or hematuria and fragment expulsions were seen. We won- dered if fragment expulsion could be considered a good indicator of a successful treatment. In many patients, reporting that they had not expelled fragments, we actually noticed that insignificant lithiasis was present.

The aim of this study is to demonstrate the presence of a stone free status or the presence of clinically insignificant residual fragments (CIRFs, defined as "asymptomatic, noninfectious, $\leq 3 \mathrm{~mm}$ fragments") in people with undetected spontaneous expulsion.

\section{MATERIALS AND METHOdS}

Between May and September 2017, we performed a total of 87 treatments. The device used for ESWL was Storz Medical Modulith ${ }^{\circledR}$ SLK. In this electromagnetic system, the shock waves are generated through a cylindrical coil with a metallic membrane in a water-filled cushion. The magnetic field of the coil causes an expansion of the membrane and the shock wave in water, which is focused by a parabolic reflector. The plastic membrane of the cushion is coupled to the patient by an ultrasound gel. The ultrasound probe is placed in line, allowing continuous monitoring of the treatment. All the patients were treated in prone position to reduce respiratory movements of the stone. They underwent sonography before treatment and four to eight weeks after treatment. No patients had radiographic targeting of stones, because of far better performance of ultrasound targeting in our hands and to avoid X-ray exposure. People lost to follow-up and with ureteral stones were excluded. Every patient was given potassium citrate and no one was given expulsive therapy after the treatment. Patients were divided into groups according to gender, previous treatments, stone diameter and position. We retrospectively reviewed the data collected and compared the results obtained using chi-square test, with significance considered at $\mathrm{p}<0.05$.

\section{Results}

We enrolled 73 consecutive patients, 53 males and 20 females. 57 patients had a single stone (mean 9,5 \pm 3.12 $\mathrm{mm})$ and 16 multiple stones. The mean age was $59 \pm 12$ years. A mean number of 3044 shock waves was administered with a maximum average energy of $0.68 \mathrm{mj} / \mathrm{mmq}$. 
Table 1 describes the main characteristics, evaluating, for each considered aspect, the presence of reported spontaneous expulsion of fragments and the presence of clinically insignificant residual fragments.

At follow up, 41 patients (56.2\%) were found stone free or with CIRFs. Among 73 patients we considered, 28 reported spontaneous expulsion, in particular, among them, 16 were stone free or with CIRFs and 12 had stones clinically significant. The association between undetected spontaneous expulsion and the presence of CIRFs (primary outcome) is considered to be not statistically significant $(\mathrm{p}=0.89)$. Patients without CIRFs required further treatments and this is considered a treatment failure (Table 2).

Among 42 patients where CIRFs were diagnosed, 25 didn't report expulsion and were divided into groups according to gender, previous treatments, stone diameter and stone position.

According to gender, 19 males and 6 females didn't report expulsion $(p=0.36)$. Patients who underwent

\section{Table 1.}

Presence of reported spontaneous expulsion of fragments and presence of clinically insignificant residual fragments in relation to different conditions.

\begin{tabular}{|lcccc|}
\hline & $\begin{array}{c}\text { Reported } \\
\text { spontaneous } \\
\text { expulsion }\end{array}$ & $\begin{array}{c}\text { No } \\
\text { expulsion }\end{array}$ & CIRFs & no CIRFs \\
\hline Males & 22 & 31 & 33 & 20 \\
\hline Females & 6 & 14 & 8 & 12 \\
\hline Previous treatments & 15 & 22 & 20 & 17 \\
\hline No previous treatments & 13 & 23 & 21 & 15 \\
\hline Stones $\leq \mathbf{1 0}$ mm & 23 & 34 & 33 & 24 \\
\hline Stones $>\mathbf{1 0}$ mm or multiple & 5 & 11 & 8 & 8 \\
\hline Lower calyx & 13 & 17 & 15 & 15 \\
\hline Middle and superior calyx & 7 & 22 & 20 & 9 \\
\hline Renal pelvis & 8 & 6 & 6 & 8 \\
\hline
\end{tabular}

\section{Table 2.}

Association between undetected spontaneous expulsion and the presence of CIRFs (primary outcome).

\begin{tabular}{|lccc|}
\hline & $\begin{array}{c}\text { Reported } \\
\text { spontaneous } \\
\text { expulsion }\end{array}$ & $\begin{array}{c}\text { No } \\
\text { expulsion }\end{array}$ & P \\
\hline $\begin{array}{l}\text { Clinically insignificant residual } \\
\text { fragments (CIRFs) }\end{array}$ & 16 & 25 & 0.89 \\
\hline Lithiasis that requires further treatments & 12 & 20 & \\
\hline
\end{tabular}

previous treatments (stenting was not considered a treatment because it does not involve fragmentation) were 11 and 14 had no previous treatments or any kind of stone fragmentation $(\mathrm{p}=0.44)$.

According to stone diameter, 17 patients with stones $\leq 10 \mathrm{~mm}$ and 8 with stones $>10 \mathrm{~mm}$ or multiple didn't report expulsion $(\mathrm{p}=0.28)$ and according to stone position, 8 with stones in lower calyx, 14 in middle and superior calyx, 3 in renal pelvis didn't report expulsion $(\mathrm{p}=0.35)$.
Table 3.

Association between undetected spontaneous expulsion and presence of CIRFs.

\begin{tabular}{|lccc|}
\hline & $\begin{array}{c}\text { Reported } \\
\text { spontaneous } \\
\text { expulsion }\end{array}$ & $\begin{array}{c}\text { No } \\
\text { expulsion }\end{array}$ & P \\
\hline Males & 14 & 19 & 0.36 \\
\hline Females & 2 & 6 & \\
\hline Previous treatments & 9 & 11 & 0.44 \\
\hline No previous treatments & 7 & 14 & \\
\hline Stones $\leq \mathbf{1 0} \mathbf{~ m m}$ & 5 & 8 & 0.28 \\
\hline Stones $>\mathbf{1 0} \mathbf{~ m m}$ or multiple & 6 & 14 & \\
\hline Lower calyx & 5 & 3 & 0.35 \\
\hline Middle and superior calyx & 13 & 17 & \\
\hline Renal pelvis & 3 & 8 & \\
\hline
\end{tabular}

Taking in account the groups our population was divided in, according to gender $(\mathrm{p}=0.36)$, previous treatments $(p=0.44)$, stone diameter $(p=0.28)$ and stone position ( $\mathrm{p}=0.35$ ), the association between undetected spontaneous expulsion and presence of CIRFs is never statistically significant (Table 3).

\section{Discussion}

Although different definitions $(1,2)$ of CIRFs (clinically insignificant residual fragments) could be found (3) and taking in account that some authors consider CIRFs a risk factor for future stone growth (2-4), they are still considered a good indicator of successful ESWL fragmentation.

The CT scan is believed to be the gold standard for residual fragments detection $(5,6)$, but we tried to avoid $\mathrm{x}$ ray exposure, especially in recurrent stone-formers (7).

The available studies about residual fragments deal mostly with medical therapy $(8,9)$, but studies about spontaneous expulsion after ESWL could not be found.

\section{Conclusions}

An undetected spontaneous expulsion of stone fragments could not be considered a sign of ESWL treatment failure.

The association between undetected expulsion and presence of CIRFs is never statistically significant if gender of the patients, previous treatments, stone diameter and stone position are considered.

\section{REFERENCES}

1. Sarica K, Yuruk E. What should we do with residual fragments. Arch Esp Urol. 2017; 70:245-250.

2. Osman MM, Alfano Y, Kamp S, et al. 5-year-follow-up of patients with clinically insignificant residual fragments after extracorporeal shockwave lithotripsy. Eur Urol. 2005; 47:860-4.

3. Chung VY, Turney BW. The success of shock wave lithotripsy (SWL) in treating moderate-sized $(10-20 \mathrm{~mm})$ renal stones. Urolithiasis. 2016; 44:441-4.

4. Khaitan A, Gupta NP, Hemal AK, et al. Post-ESWL, clinically 
insignificant residual stones: reality or myth? Urology. 2002; 59:20-4

5. Cicerello E, Merlo F, Maccatrozzo L. Management of Clinically Insignificant Residual Fragments following Shock Wave Lithotripsy. Adv Urol. 2012; 2012:320104.

6. Skolaris A, Papatsoris AG. Diagnosis and management of post percutaneous nephrolithotomy residual stone fragments. J Endourol. 2009; 23:1751-1755.
7. Elkoushy MA, Andonian S. Lifetime radiation exposure in patients with recurrent nephrolithiasis. Curr Urol Rep. 2017; 18:85.

8. Yang TX, Liao BH, Chen YT, et al. A network meta-analysis on the beneficial effect of medical expulsive therapy after extracorporeal shock wave lithotripsy. Sci Rep. 2017; 7:14429.

9. Janane A, Hamdoun A, Hajji F, et al. Usefulness of adjunctive alphal-adrenergic antagonists after single extracorporeal shock wave lithotripsy session in ureteral stone expulsion. Can Urol Assoc J. 2014; 8:E8-E11.

\section{Correspondence}

Grazia Bianchi, MD (Corresponding Author) graziuccia88@libero.it

Diego Marega, MD

Roberto Knez, MD

Stefano Bucci,MD

Carlo Trombetta, $M D$

trombcar@units.it

Università degli Studi Trieste, Urology Department - Cattinara Hospital,

Strada di Fiume 447, Trieste, Italy 